\title{
Gender patterns in domestic labour among young adults in different living arrangements in Australia
}

\author{
Lyn Craig, Abigail Powell, Judith E. Brown
}

\begin{abstract}
Most research on gender divisions of housework focuses on couple and family households. This article extends this literature to examine gender differences in domestic labour across living arrangements, with particular focus on young adults. Using time-diary data from the nationally representative Australian Bureau of Statistics (ABS) Time Use Survey (2006) it examines the amount and composition of domestic work performed by $20-34$-year-olds $(n=889)$ living with parents, in a share household, alone, or in a couple, differentiating between routine and non-routine housework tasks, and between housework done for oneself only or for the household. It finds gender differences are strongest in couple households, but pertain across living arrangements, including share houses. Also, women's domestic labour varies more by household characteristics than men's. However, there is some evidence of non-conformity to gender stereotypes, with young men living in couple relationships contributing more time on activities for the household than young men in other households.
\end{abstract}

Keywords: couples, family, gender, housework, living arrangements, share houses, young adults

\section{Introduction}

Gender differences in the division of domestic work are well-established (Bianchi and Raley, 2005). Cross-nationally, time use analyses consistently find that women do substantially more housework than men (Craig and Mullan, 2010; Fuwa, 2004; Geist, 2005; Gimenez-Nadal and Sevilla, 2012; Hook, 2005). Although men's housework has risen over time, it has done so modestly and gaps remain wide (Sayer, 2005; Sullivan, 2006). Domestic labour is an important indicator of gender (in)equity, not least because disproportionate responsibility limits women's financial opportunities compared to men's (Lachance-Grzela and Bouchard, 2010).

Existing research on the distribution of domestic work largely focuses on adults in family relationships - primarily those in heterosexual couples, either with or without children (Bianchi and Milkie, 2010; Lachance-Grzela and Bouchard, 2010). Early theoretical approaches attributed couples' gender divisions of labour to efficient specialisation for joint household benefit (Becker, 1991), marital bargaining on the basis of relative resources (Brines, 1994; Mannino and Deutsch, 2007) and/or to differences in time available net of paid work (e.g. Berk and Berk, 1979; Hiller, 1984). More recent scholars acknowledge that these ostensibly rational, gender-neutral explanations are at best partial, and poorly account for empirical gender gaps in housework (Bianchi and Milkie, 2010; England, 2011a; Pettit and Hook, 2009). Others note that the focus on the conjugal couple limits the theories' general applicability (Lachance-Grzela and Bouchard, 2010; Punch, 2001). It is not appropriate, for example, to think in terms of negotiations between partners on the basis of relative resources when looking at people living in other contexts, such as children, teenagers or adults living in the parental home, or people living alone or in shared households with no family or intimate relationships. Similarly the idea that men prioritise time in paid work and women time in unpaid 
work for the benefit of the household unit (Becker, 1991) does not readily apply to groups of unrelated individuals or people living as singletons.

This article adds to the literature by directly examining gender divisions of housework across different living arrangements. We do so with a particular focus on young adults. While there is a growing literature on the domestic work of children and teenagers (Miller, 2012; Salman Rizavi and Sofer, 2010) and, to a much lesser extent, young adults in the family home (Craig et al., 2014), there is limited empirical evidence on time devoted to domestic labour among young adults more broadly. Investigating young adults' housework presents an opportunity to move beyond couple-level explanations for gender differences, since in western countries many young adults share accommodation for a period before partnering or establishing a family (Mitchell, 2004). Young adults, particularly those in the middle classes (Kenyon and Heath, 2001), also live independently in single-person dwellings. Others continue to live in the family home for extended periods or experience a return to the family home after first leaving (de Vaus, 2004; Furlong, 2009). In Australia, 20-34-year-olds are more likely than any other age group to live in a variety of household types, including group households (ABS, 2011: authors' own analysis using ABS TableBuilder). This variety presents an opportunity to empirically examine whether and how gender divisions of labour differ across household types in this under-researched life course stage.

\section{Young people, gender and domestic labour}

Gendered behavioural practices are embedded in multiple dimensions of society, including the individual, interactional and institutional (England, 2011b; Ferree, 2010; Greenstein, 2000; Lewis, 2009; Ridgeway, 2009; Risman, 2004). Although couple analyses dominate the domestic labour literature, research among children and teenagers shows that gendered housework patterns are evident from a young age (Coltrane, 2007; Dodson and Dickert, 2004; Salman Rizavi and Sofer, 2010). For this age group, scholars have looked for explanations of gender difference in socialisation and modelling (Cunningham, 2001; Wight et al., 2009). Differences between girls' and boys' domestic contribution are thought to be engendered by parents modelling gender-stereotyped behaviour, and/or children gaining sex-stereotyped skills by more often spending time and taking part in joint activities with same-sex than opposite-sex parents (Evertsson, 2006; McHale et al., 2003). Gender socialisation theory has, however, been criticised for being too essentialist and failing to acknowledge that children actively learn to recognise prevailing gender norms (Connell, 2009b; England, 2011b). Nevertheless, a view of the family as 'the gender factory' (Berk, 1985), the primary site where gendered behaviour is produced and internalised, is still prevalent (Bianchi and Milkie, 2010). In terms of domestic work, this can mean that the amount and type of housework people do conforms to shared expectations of gendered behaviour (De Ruijter et al., 2005), with patterns passed from parents to children (Evertsson, 2006; McHale et al., 2003).

Empirical gender differences in children and teenagers' time use are also consistent with the notion of gender schema (Hilbrecht et al., 2008). This idea was developed by Bem $(1981,1983)$, who argued that people acquire culturally defined sex-specific concepts of femininity and masculinity, which are learnt, internalised, reproduced and reinforced over time. While gender schema theory goes some way to explain the pervasiveness of gender differences in domestic labour (Bianchi and Milkie, 2010; Cooke and Baxter, 2010), it fails to recognise the role of agency (Hilbrecht et al., 2008; Marler and Moen, 2005). More recent 'doing gender' theory suggests that gender is context-related and actively constructed through everyday social interactions (Connell, 2009a; Ridgeway and Correll, 2004; West and Zimmerman, 2009). Inter alia, it implies that children and young people actively learn how gender relations work and how to navigate them (Connell, 2009b). The theory of 'doing gender' further suggests that women and men derive gendered meanings from domestic labour and that 
performing it helps define and express gender relations (Bianchi et al., 2000; Connell, 2009a; Erickson, 2005). In foregrounding how gender is actively constructed, it recognises that individuals can choose when to conform to normative gender roles and when to distance themselves from particular gender identities (Connell, 2009b; Risman, 2004). Some suggest that the phenomenon of choosing not to conform to normative gender roles could be labelled 'undoing gender' (Deutsch, 2007).

'Doing gender' theory leads us to expect some differences in gendered housework patterns across living arrangements because context and interactions are different in each. In particular, young women in couple households could be expected to do more domestic labour than young women in other living arrangements. We speculate that non-family relationships would present more opportunity to at least partially 'undo' gender patterns, and that therefore share households would be most equitable. The little that is written about shared living arrangements and domestic work does suggest that unequal division of chores can cause dissatisfaction and resistance (McNamara and Connell, 2007), but no previous research has compared them empirically to other households.

It is also important to note that gender relations are enmeshed with broader institutional structures such as education, family and workforce policies, which reflexively affect behaviour and cultural attitudes (Cooke, 2006; Craig and Mullan, 2011; Hobson, 2003; Lewis, 2009). Institutional context and cultural ideas change over time, and prevalent attitudes also differ over the life course. In contemporary Australia, young women are educated to university level and enter the workforce in similar numbers to young men (ABS, 2012). Many young Australians hold more egalitarian attitudes than older people (Murray and Cutcher, 2012), which may result in a more equal division of household work (Bianchi et al., 2000). Given these factors, the life course stage of young adulthood may present a window during which gender divisions of domestic work are not pronounced, particularly in non-family households.

\section{Research focus}

In summary, compared to Australians at other stages of the life course, young Australian adults are more likely to live in non-family households (ABS, 2011). They participate relatively equally in education and market work (ABS, 2012), and have comparatively egalitarian gender attitudes (Murray and Cutcher, 2012). Yet little is known about how they allocate time to domestic labour. We address this gap in the literature, exploring whether the extent of gender differences in the amount and composition of young adults' domestic work varies according to living arrangements. Specifically our research questions are:

1. How do gender differences in young people's time in total domestic labour vary by living arrangement?

2. How does young women and men's composition of domestic labour (routine vs non-routine, done for self vs done for others) vary by living arrangement?

We look at composition because gender inequities can arise not only in the amount, but also the type of domestic activities undertaken. For example, activities including food preparation, grocery shopping, cleaning and laundry are generally regarded as routine and stereotypically female, with tasks such as outdoor work, household management and maintenance non-routine, and stereotypically male (Baxter, 2002; Kan et al., 2011). Some tasks need to be done daily, and/or at regular times, while others can be done to a more flexible timetable as and when the need arises (Sullivan, 1997). In families, men have been found more likely to do domestic labour that is nonroutine, less time consuming, has definable boundaries and where there is greater discretion around 
timing (Kan et al., 2011). Furthermore, there is a difference between doing domestic labour for one's own self-maintenance and doing it as a service to others, for the benefit of the whole household. Gender differences in serving others could be less expected outside a family setting, so we investigate this dimension of domestic labour also, innovatively dividing it into activities performed for the household and activities performed for oneself only.

\section{Data and method}

We analyse data from the 2006 Australian Bureau of Statistics Time Use Survey, which contains a nationally representative sample of the population of Australian households. All individuals aged 15 years and over in sampled households $(\mathrm{N}=7672)$ provide information in a time-diary over a 48-hour period, recording every activity they engage in, who they are with, where they are and for whom they perform each activity, to a detail level of 5-minute intervals. The surveys also collect demographic information on individual respondents and their household, from which (inter alia) we can identify living arrangement and family type.

Our sample is restricted to young people aged 20-34 who did not have children (895 young people, 1755 diaries). We exclude teenagers because they are much more likely to be living at home than in the other household types (Fussell et al., 2007). Very low numbers living elsewhere means it is not feasible to compare teenagers across different household types. We exclude young people who are parents to remove the potentially confounding effects of the well-established finding that parenthood significantly changes time use patterns and participation in domestic work (Baxter et al., 2008; Craig and Bittman, 2008; Dribe and Stanfors, 2009). After excluding missing data (12 diaries), the final sample was 889 young people (1743 diaries). Key sample characteristics are shown in Table 1.

\section{Table 1. Sample characteristics}

\begin{tabular}{lllll}
\hline & & Men (\%) & Women (\%) & Total (\%) \\
\hline Person variables & & & & \\
Living arrangements & Lives with parents & 41.6 & 38.7 & 40.3 \\
& Lives in group hhld & 13.8 & 13.6 & 13.7 \\
& Lives alone & 12.1 & 10.7 & 11.5 \\
Age & Lives in a couple & 32.5 & 37.1 & 34.5 \\
& $20-24$ & 42.0 & 48.7 & 45.0 \\
Current main activity & $25-29$ & 33.4 & 33.0 & 33.2 \\
& Employed or studying & 24.6 & 18.3 & 21.8 \\
\hline Household variables & Neither working nor studying & 89.2 & 91.9 & 90.4 \\
Number in hhld & 1-2 & 10.7 & 8.1 & 9.6 \\
SEIFA & 3+ & & & \\
& Lowest 20\% & 54.5 & 56.8 & 5.5 \\
& Second quintile & 45.5 & 43.2 & 44.5 \\
Child <15 in hhld & Third quintile & 17.4 & 16.1 & 16.8 \\
Dwelling is a house & Highest 40\% & 20.1 & 16.6 & 18.7 \\
Outsource cleaning & & 23.3 & 20.7 & 22.2 \\
Outsource gardening & & 38.8 & 46.7 & 42.3 \\
No of persons/diaries & & 4.2 & 4.1 & 4.1 \\
\hline
\end{tabular}




\section{Dependent variables}

Our interest is in domestic work, which we investigate in terms of routine and non-routine tasks. These are comprised of:

1. Routine tasks:

a. food preparation (e.g. cooking, clean-up, setting the table)

b. laundry and cleaning (e.g. washing, ironing, sorting clothes, wet and dry housework)

c. grocery shopping.

2. Non-routine tasks:

a. outdoor work (e.g. gardening, animal care, cleaning grounds, pool care)

b. household maintenance (e.g. home improvements, making furniture and furnishings, car care)

c. household management (e.g. paperwork, bills and budgeting, recycling and disposing of rubbish).

We also examine domestic work by drawing on information entered into the Time Use Survey column headed 'For whom did you do this activity?' (e.g. self, family, others in household). We create variables of total domestic work done exclusively for oneself and total domestic work done for the household. The latter variable includes activities done for both others in the household and oneself. For example, if a person has cooked dinner for the whole family, including themselves, this has been coded as done for the household. There is also a residual category of domestic work done for people outside the household, but given our focus is on gender differences within households we do not explore this in detail.

\section{Analysis plan}

We use linear regression modelling to test associations between domestic work, gender and living arrangements, and interactions between them. To answer research question 1, we examine associations between gender and living arrangements and total domestic work. For research question 2, we examine associations between the subcomponents of domestic work (routine and non-routine) and who the domestic work is done for (for oneself only and for the household) and living arrangements. We stratify the latter analyses by gender because we expect associations between covariates and the composition of domestic labour to systematically differ for men and women.

We group living arrangements into: (1) in the parental home (omitted), (2) with non-family members in a share household, (3) alone, or (4) in a couple without children.

The models control for several variables that may be independently associated with time spent in domestic tasks. We control for age, grouped into three five-year bands: 20-24 years (omitted), 2529 years and 30-34 years, because research suggests gender differences increase as children and teenagers age (Hilbrecht et al., 2008; Hill and Lynch, 1983) and that older young adults (of both genders) living with parents spend more time on non-routine activities and cooking, while older young women spend more time on laundry and cleaning (Craig et al., 2014). Time availability has been identified as a partial explicator of divisions of domestic labour (Lachance-Grzela and Bouchard, 2010) and individuals' time committed to other activities may have direct effects on how much housework they do. Therefore we control total minutes spent either working or studying on the diary day. To capture demand for housework we control for the number of people in the household (1-2(omitted)/3+), whether the dwelling is an apartment (house omitted) and whether 
there is a child under 15 in the household (yes =1). The last captures younger siblings living in the parental home, which could be associated with more housework being done.

As appropriate to the outcome variable we control for whether cleaning (routine task) or gardening (non-routine task) is outsourced (yes =1). To control for variation in socio-economic status, which may be associated with dwelling size and economic resources we include an index measure of the relative socio-economic disadvantage of the geographical area (SEIFA) in which the household is located (ABS, 2006). We place households into one of four groups depending on their position on this index (lowest 20\% [omitted]/second quintile/third quintile/highest $40 \%$ ). We use this measure rather than household income because income is unlikely to be a shared resource in non-family households, or to be a basis for bargaining over housework shares between parents and young people in the family home. SEIFA is also preferred over personal income and education since not all in our sample have completed their education or have their own income.

The data are cross-sectional, so allow us to identify associations between the independent and dependent variables, rather than direct causality. In all stages of the analysis, clustering (person within household) was accounted for and data were weighted to ensure an even distribution of days of the week and to correct for potential non-response bias.

\section{Results}

\section{Young people's time in total domestic labour}

Figure 1 shows average time spent on domestic work (height of the bars) by gender across living arrangement. Young people who live with their parents did the least amount of domestic work in total (men $40 \mathrm{mpd}$ [minutes per day], women $61 \mathrm{mpd}$ ) while those living in a couple did the most (men $74 \mathrm{mpd}$, women $125 \mathrm{mpd}$ ). Those living alone spent more time in domestic work (men $72 \mathrm{mpd}$, women $99 \mathrm{mpd}$ ) than those living in a group household (men $63 \mathrm{mpd}$, women $78 \mathrm{mpd}$ ). These descriptive findings indicate that across living arrangements women spent more time on domestic work than men and suggest that women's overall time on domestic work varies more across living arrangements than men's.

Figure 1. Mean daily minutes in routine and non-routine domestic work by living arrangements and gender

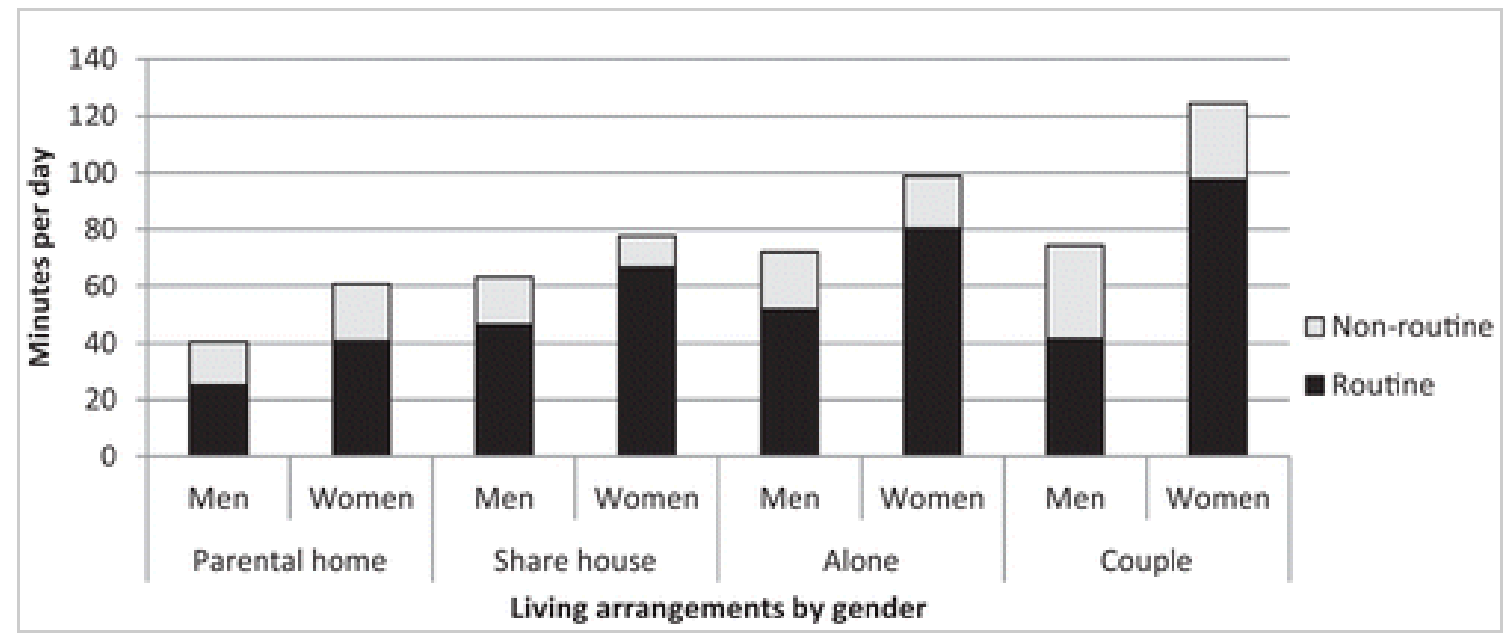


Table 2 presents results of linear regression modelling the time young people spent in all domestic tasks in total. After controlling for personal and household characteristics, women were predicted to do an average of $29 \mathrm{mpd}$ more total domestic work than men, confirming the descriptive findings. Those in couples spent more time $(27 \mathrm{mpd})$ in domestic tasks compared to those living with their parents. We entered interaction terms between gender and living arrangements, to see if the couple effect applied more to women than to men. There was a positive association between living in a couple and being female, but it was not statistically significant (not shown).

\section{Table 2. Linear regression model for total domestic work}

\begin{tabular}{|c|c|c|c|c|}
\hline \multirow[b]{2}{*}{ Female } & & \multicolumn{3}{|c|}{ Total domestic work } \\
\hline & & 29.0 & $(4.8)$ & $* * *$ \\
\hline \multirow[t]{4}{*}{ Living arrangements } & Lives with parents & & & \\
\hline & Share hhld & 8.0 & (8.3) & \\
\hline & Lives alone & 14.0 & (9.7) & \\
\hline & Lives in a couple & 26.2 & (8.5) & $* *$ \\
\hline \multirow[t]{3}{*}{ Age } & $20-24$ & & & \\
\hline & $25-29$ & 19.9 & $(6.0)$ & $* *$ \\
\hline & $30-34$ & 26.8 & (6.9) & $* * *$ \\
\hline Working and studying (mpd) & & -0.1 & $(0.0)$ & $* * *$ \\
\hline $3+$ hhld & & -28.6 & $(7.2)$ & $* * *$ \\
\hline Child $<15$ in hhld & & 18.2 & $(16.6)$ & \\
\hline Dwelling is an apartment & & -19.4 & $(6.5)$ & $* *$ \\
\hline Outsource cleaning & & -0.8 & (9.1) & \\
\hline Outsource gardening & & 8.7 & (7.3) & \\
\hline \multirow[t]{4}{*}{ SEIFA } & Lowest $20 \%$ & & & \\
\hline & Second quintile & 9.9 & $(9.2)$ & \\
\hline & Third quintile & 1.9 & (8.5) & \\
\hline & Highest 40\% & -0.4 & (7.5) & \\
\hline Intercept & & 92.6 & (13.7) & $* * *$ \\
\hline No of diaries & & 1743 & & \\
\hline R-squared adjusted & & 0.3 & & \\
\hline
\end{tabular}

Compared to those in the youngest age group (20-24 years), those in the older age groups spent more time in domestic tasks; 20 mpd more for 25-29-year-olds and $27 \mathrm{mpd}$ more for 30-34-yearolds. We entered interaction terms gender*age but these were not significant (not shown), suggesting that the differences by age apply equally to both men and women. Three other variables were associated with less time spent on domestic tasks: spending more time working or studying; living in a household with three or more people; and living in an apartment compared to a house.

\section{Young women and men's composition of domestic labour}

Figure 1 also shows daily time spent in routine and non-routine tasks by household type and gender. Within each household type women spent more time doing routine tasks than men. Women spent the most time in routine tasks when they lived in a couple $(98 \mathrm{mpd})$. Men spent the most amount of time doing routine tasks when they lived alone $(52 \mathrm{mpd})$. With the exception of young people living with their parents, young men averaged more time in non-routine tasks than young women.

Figure 2 shows mean amount of time doing domestic tasks exclusively for oneself or for the household. For completeness we included the small residual unspecified category, so as in Figure 1 the height of the bars shows mean minutes per day in total domestic labour. 
Figure 2. Mean daily minutes in domestic work done for oneself and done for the household by living arrangements and gender

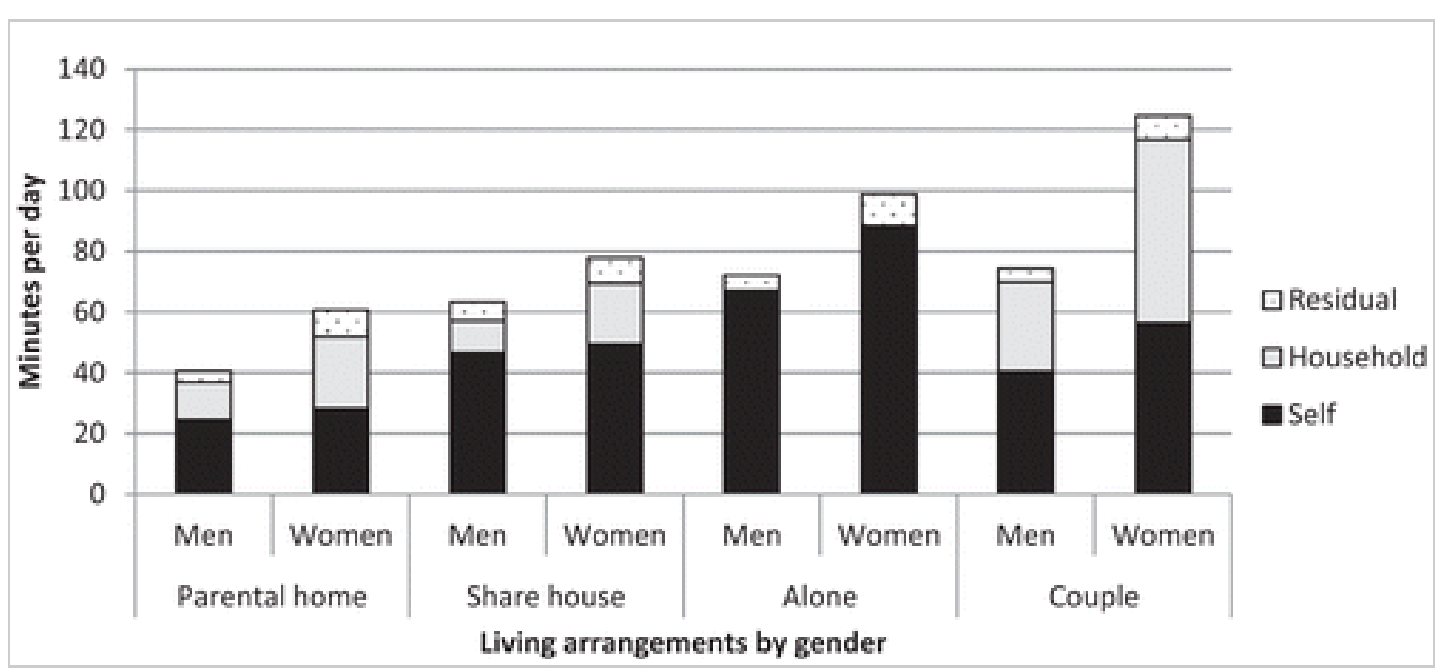

Of young people who lived with others, those in a group household averaged most time doing domestic tasks for themselves (men $47 \mathrm{mpd}$, women 50mpd). Compared to men, women spent a greater amount of time doing domestic tasks both for themselves only and for the household. However, across the household types, men spent a greater proportion of their total time in domestic work doing activities exclusively for themselves. Across all living arrangements, men's time doing tasks for themselves constituted over half their total domestic time; for women, less than half. Of those not living alone, the amount of time spent doing activities for themselves only was similar between men and women in all except couple households, so the gender differences in total domestic work largely result from tasks done for the household. Partnered women spent the largest amount of time $(60 \mathrm{mpd})$ doing domestic tasks for the household while men in share households spent the least $(11 \mathrm{mpd})$.

Table 3 presents the results of the linear regression analyses of young people's routine and nonroutine domestic tasks, and domestic activities done exclusively for oneself or performed for the household. These models are run separately for men and women given existing research documenting gender differences in domestic work and confirmed in Table 2, and we expected associations between covariates and the composition of domestic labour to systematically differ by gender.

Table 3. Linear regression models for composition of domestic work (routine and non-routine activities, done for oneself and for the household)

Living arrangements were not associated with men's time in either routine or non-routine domestic tasks. For women also, there was no association between living arrangements and non-routine activities, but women living in a couple were predicted to do more routine domestic work (33 mpd) than women who lived with their parents. Living arrangements were not associated with domestic tasks done exclusively for oneself by either gender, but compared to living with parents, living in a couple was significantly associated with more domestic work for the household (men $13 \mathrm{mpd}$; women $27 \mathrm{mpd}$ ). This suggests that the higher total domestic labour for couples is largely comprised of routine domestic work done for the household, by women. Stratifying the models and separating 
domestic labour into its components thus revealed that gender adds an additional compositional element to housework when coupled rather than living with parents.

Turning to the control variables, men aged 25-34 spent more time doing routine tasks than 20-24year-olds. For women, being aged 30-34 was associated with spending significantly more time on both routine tasks and non-routine tasks, compared to those aged 20-24. Examining for whom domestic work is done, men aged 25-34 spent significantly more time on domestic work for themselves only than 20-24 year olds. Women aged 30-34 spent significantly more time on domestic work for the household than 20-24-year-olds. In supplementary analyses (not shown) we entered interaction terms between age and the living arrangement, but found no significant differences.

For both men and women, time availability was significantly but not substantially associated with the time they spent on domestic work. For every minute spent in paid work or studying, approximately 0.1 minute less was spent in each type of domestic activity. With respect to household size, both young men and women who lived with two or more others spent less time doing non-routine domestic tasks or tasks specifically for themselves than did those who lived alone or with one other person. Young men and women spent less time engaging in non-routine domestic activities if their dwelling was an apartment (and less likely to have a yard). Living in a house was associated with less routine activity for women but not for men. Outsourcing gardening was positively associated with women's, but not men's, time in non-routine domestic tasks.

\section{Discussion and conclusion}

Using nationally representative time use data from Australia, this article analysed the amount and composition of young people's domestic work, exploring gender differences by living arrangements. The article is the first, to our knowledge, to empirically examine young people's domestic work by the type of household in which they reside. It also contributes through analysing gender divisions of domestic work in non-family households, since most research in this area has focused on family households, and particularly conjugal couples.

Young women spent more time on total domestic labour than young men, as has been consistently found for other stages of the life course (Bianchi and Raley, 2005; Craig and Bittman, 2008; Sayer, 2005). Gender differences also carried over into the composition of domestic tasks, with women spending more time on routine domestic work (food preparation, laundry and cleaning, grocery shopping) than men across all four living arrangements. Since routine activities are stereotypically female, and we might expect young people to experience greater equality because their education and workforce participation are relatively similar, this is strong evidence of the continued pervasiveness of traditional gendered behaviour. This supports arguments that gender-based classifications are learnt and accepted from an early age. However, the data also show that while gender differences are omnipresent, other factors matter too, supporting the view that agency and context play a critical additional role in how people 'do gender' in relation to housework.

Also, because women's domestic work varied more across living arrangements than men's, context appears to have a stronger influence upon women's behaviour than men's. For example, young women living in a couple averaged twice as much domestic work as young women living in the parental home; the range in men's time by living arrangement was much narrower. For both men and women, living in a couple was associated with more time spent on domestic work, but because average increases were larger for women, the gender gap was widest for this group. This living arrangement was also associated with women spending most time on routine activities and both 
men and women spending most time on domestic labour done for the household. Living arrangements had no associations with time spent on non-routine activities or tasks done only for oneself, suggesting they are particularly pertinent to female-typed tasks and activities for common household benefit.

That women do more routine domestic activities and more tasks for the household when they live in a couple supports the 'doing gender' notion that gender is actively constituted through interaction (Risman, 2009; West and Zimmerman, 2009) and underscores that the family is a primary location for constructing and perpetuating gendered behaviour (Berk, 1985; Bianchi and Milkie, 2010). The overall disparity, and the fact that it is concentrated in the more burdensome routine housework, aligns with the body of research on couples (Baxter, 2000; Bianchi and Raley, 2005; Lachance-Grzela and Bouchard, 2010). Comparing across household types confirmed that gender differences are widest when that interaction is with an intimate partner. The 'doing gender' approach seems more applicable to women than to men, however, since it does not explain why men living in a couple spend more time on activities for the household than other men. If they conformed to normative gender patterns, we might expect them to do less. However, we should remember that the gender gap in domestic labour is widest in couples, and that these men are therefore doing a smaller proportion of the whole amount performed. Also, we acknowledge that we cannot rule out potential selection bias, whereby people who live in a couple may subscribe to more 'traditional' gender values and norms.

We also found that age was an important explanatory variable. The total amount of time spent on domestic labour was higher for older young people, and interaction terms indicated that this applied equally to both genders. Examining the composition of domestic work, we found older men spent more time on routine activities and older women more time on non-routine activities (outdoor work, household maintenance and household management). Given that routine activities are female-typed and non-routine activities are male-typed (e.g. Baxter, 2002), this may suggest (since women still do more in total) that equality in domestic labour is higher among the older age groups. We also found that women aged 30-34 spent more time on domestic work for the household than younger women, net of other variables including household type. These results suggest that, as women get older, they may increasingly conform to gender norms to nurture and care for others, of which domestic work for household members would be one component. Women's investment in domestic labour may be higher when they are older because, as Bianchi et al. (2000) argue, the condition of one's home and the ability to serve others may be seen as a reflection of one's competence as a woman. We also found that household characteristics (including outsourcing, number of people in household and dwelling type) had more significant associations with women's than with men's housework, again suggesting that women's time use is more shaped by household context. This is consistent with findings that adult women's housework is more responsive to family characteristics than men's (Craig and Baxter, 2014; Sayer, 2005) and, most significantly, shows it applies to young women net of living arrangements and age.

In summary, this article added to previous inquiry by examining young people's housework across a range of household types, distinguishing by both tasks and for whom activities were done. Results underlined that investigating housework requires a gender lens in both family and non-family settings. Scholars argue that to understand how gendered behaviours arise and are perpetuated requires an integrative approach, acknowledging multiple dimensions of influence (England, 2011b; Ferree, 2010; Greenstein, 2000; Lewis, 2009; Ridgeway, 2009; Risman, 2004). Gendered housework has multiple drivers and gender-neutral perspectives do not offer a clear explanation of why 'women often continue to be responsible for completing most of the housework even when they display the individual characteristics that favour a more equal sharing' (Lachance-Grzela and Bouchard, 2010: 
776). Our findings confirm the pervasiveness of gender patterns, since women did more domestic work and more stereotypically female domestic work than men across all living arrangements. However, they also show that gender differences are further shaped by context, and that both young men and young women 'do gender' slightly differently across households. Since social and workplace policies can also structure gender divisions of household labour (Fuwa, 2004; Hook, 2005), future research comparing household types across countries with different policy frameworks could test these findings within national contexts other than Australia.

\section{Funding}

This research was supported under Australian Research Council's Discovery Projects funding scheme (DP1093311). The views expressed are those of the authors and are not necessarily those of the Australian Research Council.

\section{References}

ABS (2006) An Introduction to Socio-economic Indexes for Areas (SEIFA). Cat. no. 2039.0. Canberra: Australian Bureau of Statistics.

ABS (2011) Census of Population and Housing. Cat. no. 2068.0. Canberra: Australian Bureau of ABS (2012) Education and Work, Australia. Cat. no. 6227.0. Canberra: Australian Bureau of Statistics. Baxter, J. (2000) 'The Joys and Justice of Housework', Sociology 34: 609-31.

Baxter, J. (2002) 'Patterns of Change and Stability in the Gender Division of Household Labour in Australia, 1996-1997', Journal of Sociology 38: 399-424.

Baxter, J., Hewitt, B., Haynes, M. (2008) 'Life Course Transitions and Housework: Marriage, Parenthood, and Time on Housework', Journal of Marriage and Family 70: 259-72.

Becker, G. (1991) A Treatise on the Family. Cambridge, MA: Harvard University Press.

Bem, S.L. (1981) 'Gender Schema Theory: A Cognitive Account of Sex Typing', Psychological Review 88: 354-64.

Bem, S.L. (1983) 'Gender Schema Theory and its Implications for Child Development: Raising Genderaschematic Children in a Gender-schematic society', Signs 8: 598-616.

Berk, R.A., Berk, S.F. (1979) Labor and Leisure at Home: Content and Organization of the Household Day. New York: Sage.

Berk, S.F. (1985) The Gender Factory: The Apportionment of Work in American Households. New York: Plenum.

Bianchi, S., Milkie, M. (2010) 'Work and Family Research in the First Decade of the 21st Century', Journal of Marriage and Family 72: 705-25.

Bianchi, S., Milkie, M., Sayer, L., Robinson, J.P. (2000) 'Is Anyone Doing the Housework? Trends in the Gender Division of Household Labor', Social Forces 79: 191-228.

Bianchi, S., Raley, S. (2005) 'Time Allocation in Families', pp. 21-42 in Bianchi, S.M., Casper, L.M., King, B.R. (eds) Work, Family, Health, and Well-being. Mahwah, NJ: Erlbaum.

Brines, J. (1994) 'Economic Dependency, Gender and the Division of Labour at Home', American Journal of Sociology 100: 652-88.

Coltrane, S. (2007) 'Fatherhood, Gender and Work-Family Policies', in E.O. Wright (ed.) Real Utopias. Madison, WI: University of Wisconsin Press.

Connell, R. (2009a) 'Accountable Conduct: "Doing Gender" in Transsexual and Political Retrospect', Gender \& Society 23: 104-11.

Connell, R. (2009b) Short Introductions: Gender. Cambridge: Polity. 
Cooke, L.P. (2006) 'Policy, Preferences, and Patriarchy: The Division of Domestic Labor in East Germany, West Germany, and the United States', Social Politics: International Studies in Gender, State \& Society 13: 117-43.

Cooke, L.P., Baxter, J. (2010) "Families" in International Context: Comparing Institutional Effects across Western Societies', Journal of Marriage and Family 72: 516-36.

Craig, L., Baxter, J. (2014) 'Domestic Outsourcing, Housework Shares and Subjective Time Pressure: Gender Differences in the Correlates of Hiring Help', Social Indicators Research. Online First doi 10.1007/s11205-014-0833-1.

Craig, L., Bittman, M. (2008) 'The Effect of Children on Adults' Time-use: An Analysis of the Incremental Time Costs of Children in Australia', Feminist Economics 14: 57-85.

Craig, L., Mullan, K. (2010) 'Parenthood, Gender and Work-Family Time in USA, Australia, Italy, France and Denmark', Journal of Marriage and Family 72: 1344-61.

Craig, L., Mullan, K. (2011) 'How Mothers and Fathers Share Childcare: A Cross-national Time-diary Comparison', American Sociological Review 76: 834-61.

Craig, L., Powell, A., Brown, J.E. (2014) 'Co-resident Parents and Young People Aged 15-34: Who Does What Housework?', Social Indicators Research 121(2): 569-88.

Cunningham, M. (2001) 'Parental Influences on the Gendered Division of Housework', American Sociological Review 66: 184-203.

De Ruijter, E., Treas, J.K., Cohen, P.N. (2005) 'Outsourcing the Fender Factory: Living Arrangements and Service Expenditures on Female and Male Tasks', Social Forces 84: 305-22.

de Vaus, D . (2004) Diversity and Change in Australian Families: Statistical Profiles. Melbourne: Australian Institute of Family Studies.

Deutsch, F. (2007) 'Undoing Gender', Gender \& Society 21: 106-27.

Dodson, L., Dickert, J. (2004) 'Girls' Family Labor in Low-income Households: A Decade of Qualitative Research', Journal of Marriage and Family 66: 318-32.

Dribe, M., Stanfors, M. (2009) 'Does Parenthood Strengthen a Traditional Household Division of Labor? Evidence from Sweden', Journal of Marriage and Family 71: 33-45.

England, P. (2011a) 'Missing the Big Picture and Making Much Ado about Almost Nothing: Recent Scholarship on Gender and Household Work', Journal of Family Theory \& Review 3: 23-6.

England, P. (2011b) 'Reassessing the Uneven Gender Revolution and its Slowdown', Gender \& Society 25: 113-23.

Erickson, R.J. (2005) 'Why Emotion Work Matters: Sex, Gender, and the Division of Household Labor', Journal of Marriage and Family 67: 337-51.

Evertsson, M. (2006) 'The Reproduction of Gender: Housework and Attitudes towards Gender Equality in the Home among Swedish Boys and Girls', British Journal of Sociology 57: 415-36.

Ferree, M.M. (2010) 'Filling the Glass: Gender Perspectives on Families', Journal of Marriage and Family 72: 420-39.

Furlong, A. (2009) 'Changing Contexts, Changing Lives', in A. Furlong (ed.) Handbook of Youth and Young Adulthood: New Perspective and Agendas. New York: Routledge.

Fussell, E., Gauthier, A., Evans, A. (2007) 'Heterogeneity in the Transition to Adulthood: The Cases of Australia, Canada, and the United States', European Journal of Population 23: 389-414.

Fuwa, M. (2004) 'Macro-level Gender Inequality and the Division of Household Labor in 22 Countries', American Sociological Review 69: 751-67.

Geist, C. (2005) 'The Welfare State and the Home: Regime Differences in the Domestic Division of Labour', European Sociological Review 21: 23-41.

Gimenez-Nadal, J.I., Sevilla, A. (2012) 'Trends in Time Allocation: A Cross-country Analysis', European Economic Review 56: 1338-59.

Greenstein, T. (2000) 'Economic Dependence, Gender and the Division of Labour in the Home', Journal of Marriage and Family 62: 322-35. 
Hilbrecht, M., Zuzanek, J., Mannell, R. (2008) 'Time Use, Time Pressure and Gendered Behavior in Early and Late Adolescence', Sex Roles 58: 342-57.

Hill, J.P., Lynch, M.E. (1983) 'The Intensification of Gender-related Role Expectations during Early Adulthood', pp. 201-28 in Brooks-Gunn, J., Peterson, A.C. (eds) Girls at Puberty: Biological and Psychosocial Perspectives. New York: Plenum.

Hiller, D.V. (1984) 'Power Dependence and Division of Family Work', Sex Roles 10: 1003-19.

Hobson, B. (2003) Recognition Struggles and Social Movements: Contested Identities, Agency and Power. Cambridge: Cambridge University. Press.

Hook, J. (2005) 'Still Specialized? Cross National Trends in the Division of Household Labor 19651998 ', paper presented at the American Sociological Association Annual Meeting, Philadelphia, 13-16 August.

Kan, M.Y., Sullivan, O., Gershuny, J. (2011) 'Gender Convergence in Domestic Work: Discerning the Effects of Interactional and Institutional Barriers from Large-scale Data', Sociology 45: 23451.

Kenyon, E., Heath, S. (2001) 'Choosing This Life: Narratives of Choice amongst House Sharers', Housing Studies 16: 619-35.

Lachance-Grzela, M., Bouchard, G. (2010) 'Why Do Women Do the Lion's Share of Housework? A Decade of Research', Sex Roles 63: 767-80.

Lewis, J. (2009) Work-Family Balance, Gender and Policy. Cheltenham: Edward Elgar.

Mannino, C.A., Deutsch, F.M. (2007) 'Changing the Division of Household Labor: A Negotiated Process between Partners', Sex Roles 56: 309-24.

Marler, J.H., Moen, P. (2005) 'Alternative Employment Arrangements: A Gender Perspective', Sex Roles 52: 337-49.

McHale, S., Crouter, A., Tucker, C. (2003) 'Family Context and Gender Role Socialization in Middle Childhood: Comparing Girls to Boys and Sisters to Brothers', Child Development 70: 9901004.

McNamara, S., Connell, J. (2007) 'Homeward Bound? Searching for Home in Inner Sydney's Share Houses', Australian Geographer 38: 71-91.

Miller, P. (2012) ‘Do Australian Teenagers Work? Why We Should Care', Feminist Economics 18: 124.

Mitchell, B. (2004) 'Home, but Not Alone: Socio-cultural and Economic Aspects of Canadian Young Adults Sharing Parental Households', Atlantis 28: 115-25.

Murray, J., Cutcher, L. (2012) 'Gendered Futures, Constrained Choices: Undergraduate Perceptions of Work and Family', Journal of Population Research 29: 315-28.

Pettit, B., Hook, J. (2009) Gendered Tradeoffs: Family, Social Policy, and Economic Inequality in Twenty-one Countries. New York: Russell Sage.

Punch, S. (2001) 'Household Division of Labour: Generation, Gender, Age, Birth Order and Sibling Composition', Work, Employment \& Society 15: 803-23.

Ridgeway, C. ( 2009) 'Framed Before We Know It: How Gender Shapes Social Relations', Gender \& Society 23: 145-60.

Ridgeway, C., Correll, S. (2004) 'Unpacking the Gender System: A Theoretical Perspective on Gender Beliefs and Social Relations', Gender \& Society 18: 510-31.

Risman, B.J. (2009) 'From Doing to Undoing: Gender as We Know It', Gender \& Society 23: 81-4.

Risman, B.J. (2004) 'Gender as a Social Structure: Theory Wrestling with Activism', Gender \& Society 18: 429-50.

Salman Rizavi, S., Sofer, C. (2009) 'The Third Partner in the Household: An Analysis of Children's Household Work', paper presented at the 31st IATUR Conference, Leuphana University, Lüneberg, 23-25 September.

Sayer, L. (2005) ‘Gender, Time and Inequality: Trends in Women's and Men's Paid Work, Unpaid Work and Free Time', Social Forces 84: 285-303. 
Sullivan, O. (1997) 'Time Waits for No (Wo)Man: An Investigation of the Gendered Experience of Domestic Time', Sociology 31: 221-39.

Sullivan, O. (2006) Changing Gender Relations, Changing Families: Tracing the Pace of Change over Time. New York: Rowman and Littlefield.

West, C., Zimmerman, D. (2009) 'Accounting for Doing Gender', Gender \& Society 23: 112-22.

Wight, V., Price, J., Bianchi, S., Hunt, B. (2009) 'The Time Use of Teenagers', Social Science Research 38: 792-809.

\section{Author biographies}

Lyn Craig is an Australian Research Council (ARC) Queen Elizabeth II Fellow at the Social Policy Research Centre (SPRC), University of New South Wales (UNSW). Her research interests include the intersections between the family and the economy, gender equity, work-family balance and comparative family and social policy.

Abigail Powell is an ARC Discovery Early Career (DECRA) Fellow at the Centre for Social Impact, UNSW. She is a mixed methods researcher with expertise in gender diversity, work-life balance, young people and social policy.

Judith E. Brown is a Research Officer at the SPRC, UNSW. She specialises in applied social statistical analysis and has considerable expertise in time-use analysis. She has published the fields of psychooncology, social policy, sociology and health psychology. 